\title{
Análise regional de Chapecó e de cinco cidades de influência
}

\author{
Claudio Machado Maia ${ }^{1}$ \\ Gabriel Pitschel ${ }^{2}$
}

\begin{abstract}
Resumo
O presente estudo tem como objetivo servir de ponto de partida para pesquisas que visem trabalhar o desenvolvimento regional endógeno sustentável da Microrregião de Chapecó. Para isto, faz-se uso do Quociente Locacional $(\mathrm{QL})$, medida de especialização bastante difundida na análise regional, na identificação de potencialidades e gargalos presentes na estrutura produtiva da região. A investigação dos QL's dos macrossetores agropecuário, industrial e de serviços, na região e nos municípios que a compõem, permitem, juntamente com dados complementares, levantar hipóteses sobre aspectos econômicos e sociais, com vistas à identificação de potencialidades e gargalos regionais. Em termos metodológicos, este estudo realiza uma pesquisa exploratória a partir de dados obtidos por meio do Instituto Brasileiro de Geografia e Estatística (IBGE). A pesquisa não indica a centralidade da indústria, mas sinaliza o crescimento dos serviços auxiliares e de indústrias subsidiárias como base para produzir e comercializar eficientemente o produto de exportação da região analisada, a partir do desenvolvimento de indústrias locais para servirem ao consumo local e conduzir à ampliação da base de exportação.
\end{abstract}

Palavras-chave: Microrregião de Chapecó. Desenvolvimento endógeno. Região.

\begin{abstract}
The present study aims to serve as a starting point for research aimed at working the sustainable endogenous regional development of the Chapecó Microregion. In order to do this, we use the Locational Quotient (QL), a measure of specialization that is widely used in the regional analysis, in the identification of potentialities and bottlenecks present in the productive structure of the region. The investigation of the QL's of the agricultural, industry and services macrossetores in the region and in the municipalities that make up it, together with the complementary data, allow the hypothesis of economic and social aspects with a view to the identification of potentialities and regional bottlenecks. In methodological terms, this study performs an exploratory research based on data obtained through the Brazilian Institute of Geography and Statistics (IBGE). The research does not indicate the centrality of the industry, but signals the growth of auxiliary services and subsidiary industries as a basis for producing and efficiently marketing the export product of the analyzed region, from the development of local industries to serve local consumption and lead to the expansion of the export base.
\end{abstract}

Keywords: Microregion of Chapecó. Endogenous development. Region.

\section{Introdução}

Este artigo apresenta reflexões a partir das quais se investigam dinâmicas regionais, sobretudo as potencialidades das distintas regiões econômicas no oeste catarinense, nomeadamente de Chapecó e de outras cinco cidades influentes (Concórdia, Xanxerê, São

\footnotetext{
${ }^{1}$ Doutor em Desenvolvimento Rural. Professor do Programa de Pós-Graduação em Políticas Sociais e Dinâmicas Regionais da UNOCHAPECÓ. claudiomaia.dr@hotmail.com

2 Economista. pitschel.gabriel@unochapeco.edu.br
} 
Miguel do Oeste, Maravilha e Pinhalzinho), visando-se ao fomento das atividades nas quais cada região se mostra mais competitiva. Entende-se que, uma vez definidos os segmentos nos quais cada região é mais competitiva, é possível levar à frente uma política coordenada entre os diversos atores e modelos organizacionais.

Conforme Riedl, Maia e Schuster (2008), vários são os trabalhos que estão sendo realizados que se preocupam com as desigualdades regionais. Tal é a preocupação com a ocupação dos espaços nos processos de desenvolvimento, que o êxito dos estudos em economia regional está sujeito ao conhecimento das particularidades e dos potenciais das regiões que são objeto de investigação.

Conforme Becker (2002, p. 88), “o processo de desenvolvimento regional deixa de ser pura e simplesmente uma questão quantitativa e adquire crescentes dimensões qualitativas, através do pleno reconhecimento e do pleno desabrochar das diversidades regionais", o que nos remete à necessidade de medir e considerar perfis e produtividades espaciais diferentes, segundo os lugares diferentes, e chegar a processos de desenvolvimento diferentes. Para Paiva (2005), região é como o resultado de um processo de regionalização, processo em função dos objetivos daqueles que o colocam em curso.

Conforme Paiva (2006a), o principal indicador das potencialidades de desenvolvimento endógeno de uma região é a sua especialização atual, aproximando a ideia de "potencial", baseando-se nas alternativas existentes para a região, suas possibilidades futuras e suas chances de superação, da ideia de "especialização", a qual trata de trajetórias já trilhadas, de opções já feitas. Sendo assim, possuir um adequado diagnóstico das especificidades das dinâmicas produtivas é indispensável para fundamentar projetos e políticas de desenvolvimento local/regional. Tal fato é justificado, assim, pelo esforço de identificação do grau de especialização e concentração das atividades produtivas, para qualificar as aglomerações geográficas e setoriais que podem ser potencializadas por ações conjuntas, ou no sentido de incrementar a cooperação entre as unidades produtivas, ou no direcionamento das políticas públicas.

Parte da inspiração deste estudo é devido a um caminho teórico-metodológico empírico, onde se depara com um conjunto de autores que, embora há muito tempo sejam referência teórica, aqui serão lidos como teóricos do desenvolvimento regional. Uma das 
inspirações para este estudo recebe a contribuição de Paiva $(2004)^{2}$, onde se afirma que há muito terreno a ser percorrido até se obter um programa de identificação das potencialidades econômicas regionais que nos contemple plenamente. Outra inspiração surge a partir da experiência realizada nas Conferências Estaduais e Nacional de Desenvolvimento Regional ${ }^{3}$. Também se destacam vários trabalhos realizados sobre as desigualdades regionais (MACEDO; MONASTERIO, 2016; PAIVA, 2013 e 2004; COSTA; PETER, 2011; COSTA;;NIJKAMP, 2009; DINIZ; CROCCO, 2006; BECKER, 2002; DINIZ, 2000; BENKO, 1999; NORTH, 1959, 1955), e tal é a preocupação com a ocupação dos espaços nos processos de desenvolvimento que o êxito dos estudos em economia regional está sujeito ao conhecimento das particularidades e dos potenciais das regiões que são objeto de investigação, já que, conforme Paiva (2006a), o principal indicador das potencialidades de desenvolvimento endógeno de uma região é a sua especialização atual. Aproxima, assim, a ideia de potencial, baseado nas alternativas existentes para a região, em suas possibilidades futuras e suas chances de superação, da ideia de especialização, a qual trata de trajetórias já trilhadas, de opções já feitas.

\section{Estratégia metodológica}

Se o ponto de chegada de uma pesquisa sobre as potencialidades regionais do oeste catarinense deve envolver a identificação dos territórios submetidos a um mesmo padrão de dinâmica econômica, o ponto de partida só pode ser a subdivisão territorial consolidada nas práticas políticas cotidianas, o que, em Santa Catarina, vale dizer que tanto poderiam ser tomadas as associações de municípios como regiões econômicas, no sentido das definições de Hoover e Fischer, Costa e Nijkamp, assim como a área de influência de Chapecó e de outras cinco cidades influentes. E isto porque a hipótese simplificadora nos permite ir diretamente ao tema que organiza este estudo, a definição dos indicadores que devem ser construídos (dada à grande disponibilidade de dados secundários), com vistas a garantir a máxima consistência e determinação ao diagnóstico preliminar de potencialidades regionais.

\footnotetext{
2 Em seu trabalho intitulado "Como se identifica o potencial de uma região?".

3 Da tentativa de formular uma política regional de uma maneira diferente, de suas metas, objetivos, instrumentos e medidas.
} 
Sendo assim, a delimitação deste estudo envolve, objetivamente, Chapecó, Concórdia, Xanxerê, São Miguel do Oeste, Maravilha e Pinhalzinho, municípios pertencentes ao oeste de Santa Catarina.

A escolha dos municípios baseou-se em resultados de pesquisas apresentados em estudos anteriores (MAIA; ROLIM, 2015; VILLELA; ALBA; MAIA; ARRUDA, 2015; MAIA; SANTIN; ALBA; VILLELA, 2014; MAIA; FUJITA; ALBA, 2013; FUJITA; MATIELLO; ALBA, 2009) e no documento do IBGE (2007) acerca da região de influência das cidades, que privilegiou a análise de aspectos e dados econômicos e populacionais, a partir de fontes primárias e secundárias, além de trabalhos de campo.

No primeiro momento da pesquisa realizada para a produção deste artigo, trabalhase com dados estatísticos secundários, buscando-se definir um diagnóstico preliminar das potencialidades regionais. No segundo momento da referida pesquisa, realiza-se uma pesquisa de campo, com levantamento primário de dados e informações, buscando-se testar a consistência e a economicidade das hipóteses sugeridas no diagnóstico preliminar.

\section{Pressuposto da análise regional}

Considerando-se a heterogeneidade da região oeste de Santa Catarina, defronta-se com um dos principais problemas das análises regionais. As regionalizações não partem de regiões objetivamente determinadas, e, sim, de regiões tradicionais, ou regiões políticoadministrativas. Conforme Boudeville (in PAIVA, 2006c, p. 4), o problema era que os dados regionais são agrupados por unidades administrativas, e esses agrupamentos políticos não coincidem com as diferenciações nem com as organizações econômicas, nem mesmo com uma região polarizada. De acordo com Breitbach (1988, p. 39), este tipo de região polarizada "expressa-se num meio urbano em que as atividades industrial e comercial preponderem e irradiam fluxos de trocas de bens e serviços com o campo e cidades satélites [...] sob a influência do pólo".

As regionalizações político-administrativas proporcionam três vantagens para a investigação e a coleta de dados: (1) permitem que se opere com bases de dados tal como são usualmente disponibilizadas (a partir de limites territoriais definidos no plano político- 
administrativo); (2) são solidárias com o senso comum consolidado e os interesses imediatos de gestores públicos das distintas instâncias administrativas; e (3) poupam o pesquisador do trabalho de re-regionalizar. Entretanto, essa facilidade de opção induz a conclusões erradas. Primeiro, porque sempre há heterogeneidades nas sub-regiões reais que compõem uma macrorregião. Segundo, porque tais heterogeneidades são decorrentes das divisões do território, que não obedecem a nenhum critério lógico e/ou metodológico, por isso simplesmente aceitam divisões político-administrativas.

Quanto aos limites territoriais definidos no plano político-administrativo, não se defende o ponto de vista segundo o qual se deveria ignorar o padrão no qual são disponibilizadas as bases de dados. Diz-se, sim, é que não há por que subordinar-se a elas: agregar (e, por vezes, até cindir) é possível e, inúmeras vezes, necessário. E esta agregação (ou cisão) não tem que se submeter aos padrões tradicionais, mas pode e deve ser definida pelo pesquisador. Por outro lado, quanto às divisões político-administrativas, numa perspectiva geográfica específica, alguns autores diriam que não se está falando do conceito de região e, sim, de território. Território, dizendo respeito a um espaço definido por relações de poder que, neste caso, teria por base a dimensão jurídico-política (relações espaço-poder institucionalizadas) (HAESBAERT; SOUZA in PAIVA, 2006, p. 7).

Sendo assim, neste estudo, a opção de pesquisa indica como limites territoriais Chapecó, Concórdia, Xanxerê, São Miguel do Oeste, Maravilha e Pinhalzinho, municípios pertencentes ao oeste de Santa Catarina.

\section{Pressupostos da medida de especialização: o Quociente Locacional (QL)}

O ponto de partida da pesquisa é impositivo e condição sine qua non para a definição das características da pesquisa primária, pois não se pode definir sequer o modelo de levantamento primário de informações (o tipo e o padrão de seleção da amostra, o instrumento de coleta de dados, os recursos humanos, materiais e temporais necessários à realização do levantamento e da sistematização dos dados coletados, etc.), sem que se responda, à luz dos dados secundários, às seguintes questões cruciais: Qual(is) a(s) nossa(s) principal(is) suspeita(s) de potencial(is)? Qual(is) o(s) nosso(s) principal(is) suspeito(s) de gargalo(s)? No caso de haver diversos suspeitos de potencial e gargalo, é possível 
hierarquizá-los? O que fica mal explicado na análise dos dados secundários? Onde aparecem resultados inesperados, problemas e contradições? Que trabalho de pesquisa seria necessário para o adequado enfrentamento desses problemas e contradições? (PAIVA, 2004, p. 13).

E, para responder a esse conjunto de questões de forma determinada, analisa-se a região-objeto a partir de recortes cada vez mais restritivos e específicos (no sentido região, microrregião, município), comparando as medidas pertinentes a cada um desses recortes com as medidas equivalentes para regiões de referência, definidas em patamares superiores de agregação (no sentido nação, macrorregião, região, microrregião), numa racionalidade analítico interpretativa que remete a uma medida clara da especialização produtiva regional, sendo que, nesta pesquisa, nomeadamente, será adotada a racionalidade da noção de Quociente Locacional (QL).

Para delimitar especializações dentro da região e apontar algumas das características da estrutura produtiva local e identificar padrões regionais de crescimento econômico, utiliza-se, com certa frequência, um conjunto de medidas de localização e especialização, como métodos de análise regional, entre os quais o mais difundido na literatura econômica é o Quociente Locacional (QL) (HADDAD, 1989).

Segundo Paiva (2004), a medida de participação (neste caso a especialização relativa) mais utilizada é a percentagem dos empregos gerados no setor/segmento vis-à-vis ao conjunto dos empregos do território. Para isto adota-se:

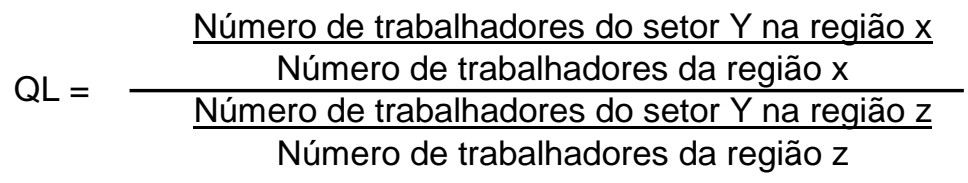

No caso acima, a região $\mathrm{X}$ representa a microrregião (município, região) da qual se busca a participação relativa em função da região Z, que representa a macrorregião (estado, nação).

A racionalidade de utilização do QL para análise regional é desenvolvida neste estudo para a caracterização da área de influência de Chapecó e outras cinco cidades influentes, nomeadamente Concórdia, Xanxerê, São Miguel do Oeste, Maravilha e Pinhalzinho, 
sobretudo, apresentando uma caracterização baseada na investigação dos QLs dos macrossetores agropecuário, industrial e serviços, bem como dos municípios que compõem a referida região, com vistas a identificar o nível de especialização dos respectivos setores e/ou produtos e serviços ali existentes. Por outro lado, também serão utilizadas outras técnicas analíticas, o que aumenta a capacidade de compreensão dos problemas que estão sendo investigados (HADDAD, 1989).

Conforme Paiva (2006b), o quociente de localização informa não apenas se o objeto de mensuração é ou não especializado (e o quanto é especializado), mas também a medida em que o objeto não apresenta especialização.

Neste trabalho, optou-se por um pseudo-QL, obtido a partir do cruzamento das informações disponíveis. Neste caso, o VAB Total e o VAB dos macrossetores agropecuário, indústria e serviços, para cada segmento em análise (município e região de pesquisa), são relativos à região de referência (região, estado), de forma que o Quociente Locacional (QL) para o macrossetor agropecuária toma a seguinte forma:

$$
\mathrm{QL}=\frac{\frac{V A B \text { da agropecuária no município }}{V A B \text { total do município }}}{\frac{V A B \text { da agropecuária na região } S C}{\text { VAB total na região SC }}}
$$

Dada à característica de especialização relativa sinalizada pelo Quociente Locacional, adota-se, para fins práticos: $\mathrm{QL} \leq 1$ como indicador de setores (macrossetores em nossa pesquisa) que não possuem especialização relativa; e $Q L>1$ como indicador de especialização relativa, sendo que quanto maior o QL, maior a especialização relativa do setor.

\subsection{Apresentação e análise dos resultados}

Os dados apresentados partiram da re-regionalização do oeste do estado de Santa Catarina através de pesquisas e estudos anteriores (MAIA e ROLIM, 2015; VILLELA, ALBA, MAIA e ARRUDA, 2015; MAIA, SANTIN, ALBA e VILLELA, 2014; MAIA, FUJITA, ALBA, 2013; FUJITA, MATIELLO e ALBA, 2009). A re-regionalização identifica a nova região de pesquisa 
formada por Chapecó e outros cinco municípios, nomeadamente de Concórdia, Maravilha, São Miguel do Oeste, Pinhalzinho e Xanxerê. Na Figura 1, identificam-se os municípios de análise.

Figura 1: Localização dos municípios que compõe a região de pesquisa

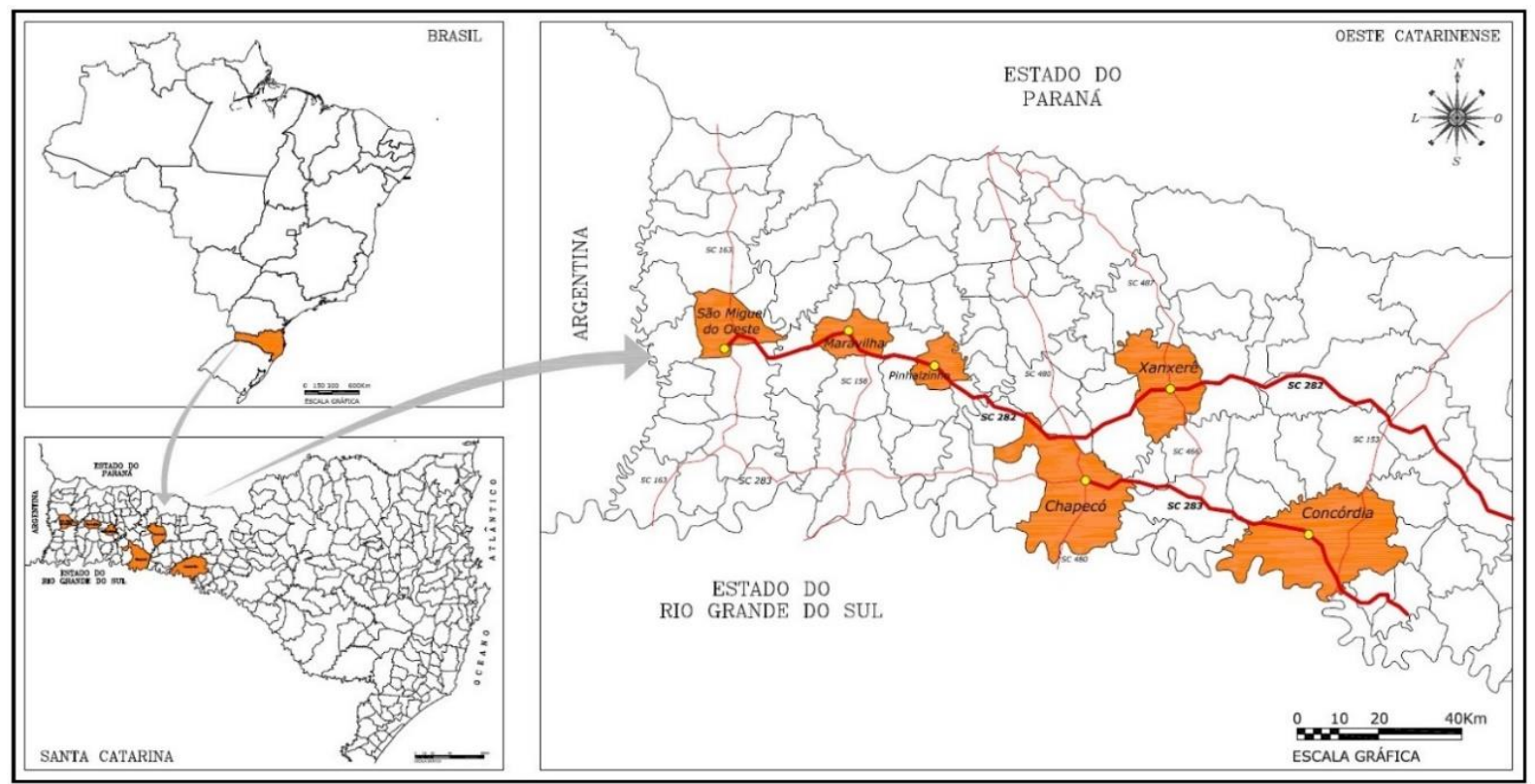

Fonte: Base Cartográfica: IBGE, 2005. Edição: Dione Ludwig (2012).

A estrutura produtiva da região de pesquisa (aqui denominada Microrregião de Chapecó), comparativamente com o total estadual, possui predomínio no setor industrial, o qual é responsável por 6,39\% do VAB (Valor Adicionado Bruto) da indústria no estado de Santa Catarina no ano de 2014 (Gráfico 1). Os setores de serviços e agropecuário contribuíram com $5,12 \%$ e 4,38\%, respectivamente, na estrutura do VAB de seus respectivos setores no estado. No mesmo ano, a região foi responsável por $5,46 \%$ do VAB total do estado de Santa Catarina (Gráfico 2). 


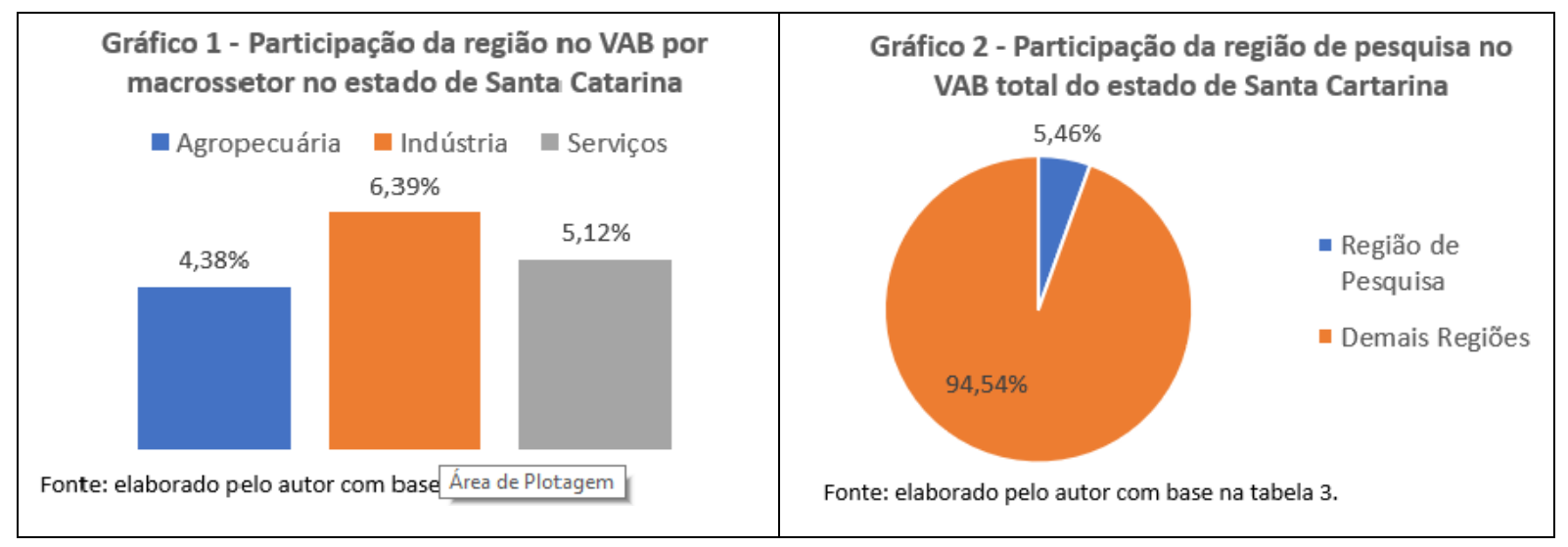

A estrutura produtiva da Microrregião de Chapecó, comparativamente aos seis municípios que a compõem, apresenta predomínio no setor de serviços, sendo este responsável por 62,32\% do VAB total da região, em 2010, e 59,55\% em 2014. Em seguida, observa-se uma expressiva participação da indústria, representando, em 2010 e 2014, $32,02 \%$ e $35,49 \%$, respectivamente, do VAB total da região. O setor agropecuário foi o que apresentou menor participação relativa no VAB total da região, apresentando uma participação relativa de 5,65\% e 4,96\%, respectivamente, para 2010 e 2014 (Gráfico 3).

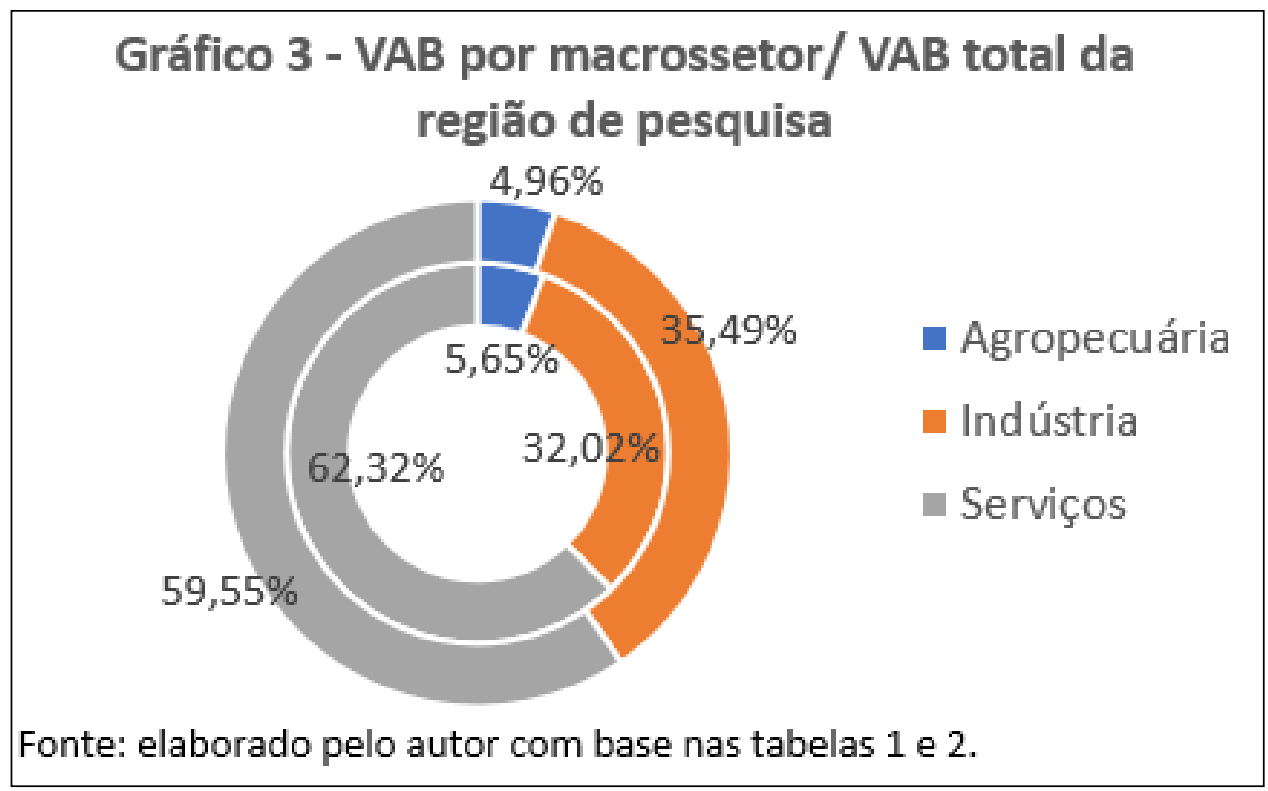

A análise da composição relativa do VAB entre os municípios revela uma participação expressiva de Chapecó (aqui considerado como polo regional), município responsável por 
54,42\% da composição do VAB total da região (Gráfico 4), o que é trivial, uma vez que Chapecó agrega 50,49\% da população total da região (Gráfico 5).

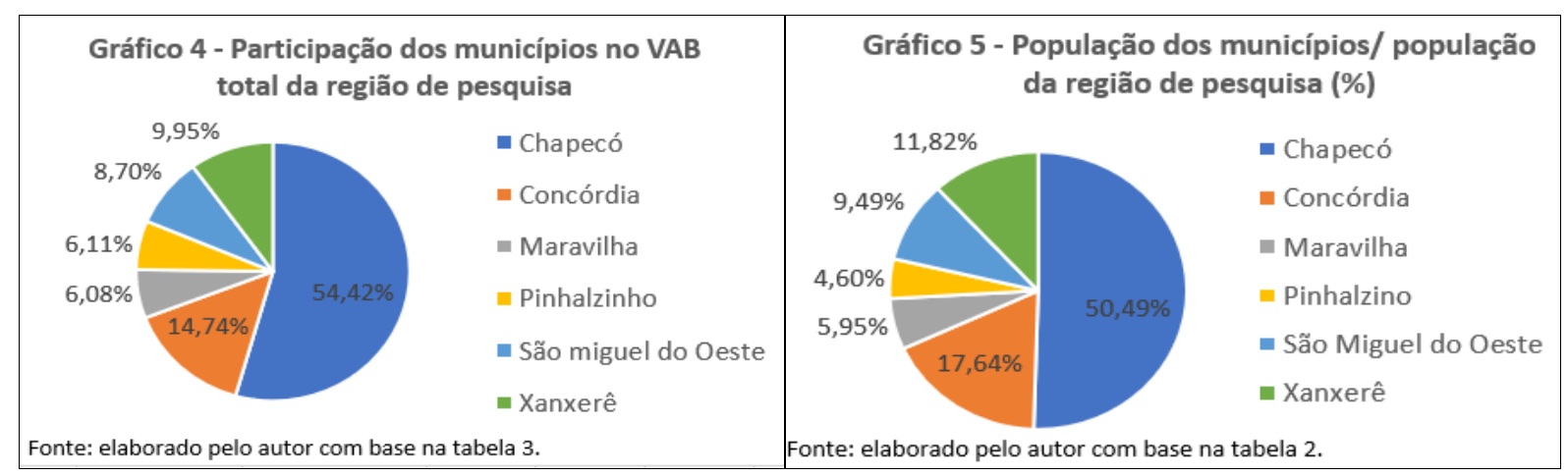

A partir dos Gráficos 6 e 7, é possível observar de maneira intuitiva a dinâmica entre os macrossetores produtivos (agropecuária, indústria e serviços), que revela o predomínio do setor de serviços em todos os municípios no ano de 2010, representando quase sempre mais que $50 \%$ do VAB total, chegando a representar 66,5\% em Chapecó e 63,2\% em São Miguel do Oeste.

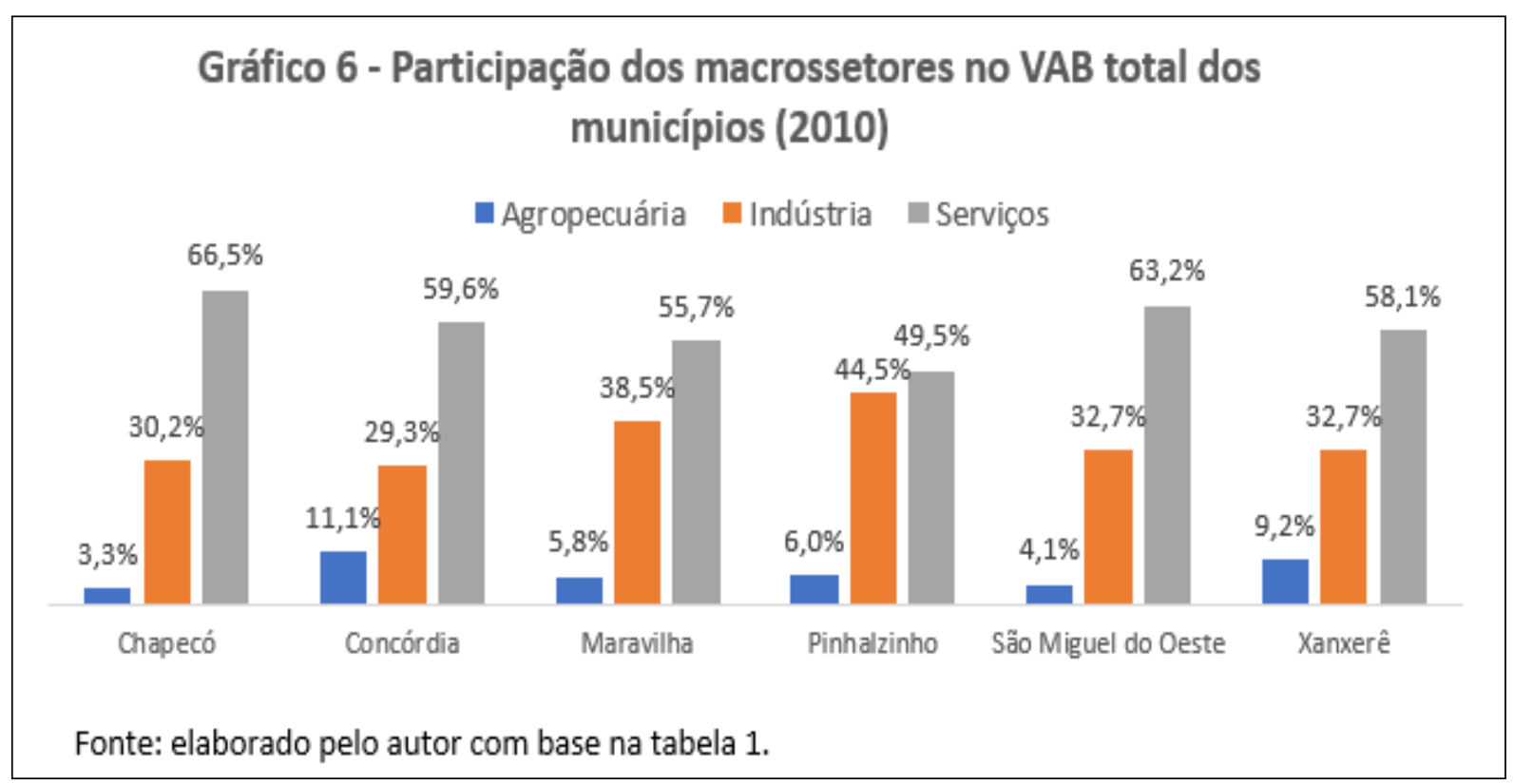


Em 2014, o predomínio do setor de serviços mantém-se para quatro dos seis municípios, com exceção de Maravilha e Pinhalzinho, cujo predomínio passou a ser da indústria com um VAB de 50,23\% e 47,63\%, respectivamente.

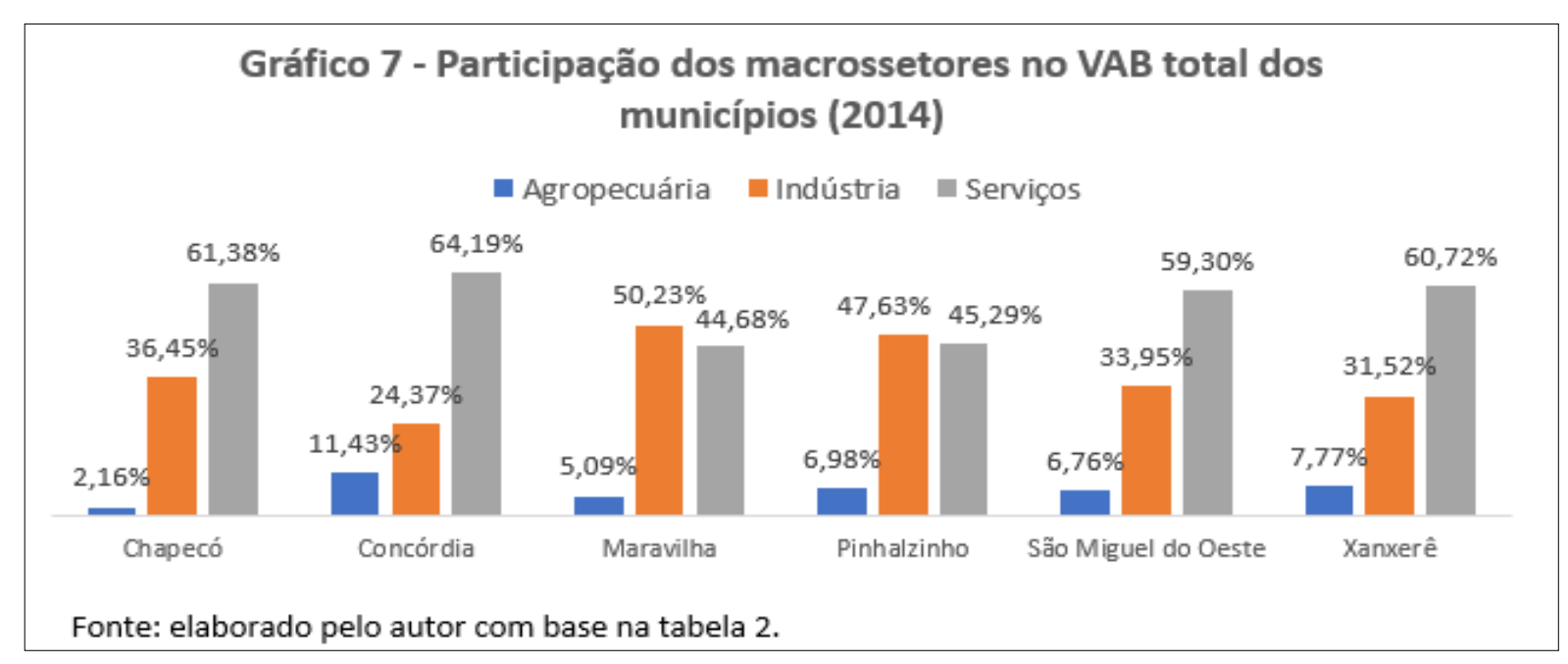

Referente ao crescimento da participação da indústria no VAB total, Maravilha foi o município que mais se destacou, apresentando um crescimento de 30,47\% no setor entre 2010 e 2014, seguido por Chapecó (20,70\%), Pinhalzinho (7,03\%) e São Miguel do Oeste (3,82\%). Concórdia e Xanxerê tiveram uma redução na participação da indústria no VAB total de $16,83 \%$ e 3,61\%, respectivamente. O setor agropecuário nos municípios da região teve pouca variação e não apresenta valores expressivos.

Quanto à apropriação e geração de renda, é possível identificar, por meio da relação Rendimento Domiciliar (RD) Anual per capita/PIB per capita, o percentual de apropriação da renda gerada por parte dos indivíduos de uma determinada região. Para isto, com base nas Tabelas 1 e 2, é possível identificar o percentual de apropriação da renda na Microrregião de Chapecó e seus seis municípios nos referidos anos de 2010 e 2014. 
Tabela 1 - Indicadores de população e Macrossetores produtivos da Região de pesquisa (2010)

\begin{tabular}{|c|c|c|c|c|c|c|c|c|c|c|}
\hline Municípios & $\begin{array}{c}\text { População Total } \\
\text { (n }{ }^{0} \text { habitantes) }\end{array}$ & $\begin{array}{l}\text { População } \\
\text { Urbana ( }{ }^{0} \\
\text { habitantes) }\end{array}$ & $\begin{array}{c}\text { População } \\
\text { Rural }\left(n^{0}\right. \\
\text { habitantes) }\end{array}$ & $\begin{array}{c}\text { Pop } \\
\text { rural/Pop } \\
\text { Total (\%) }\end{array}$ & $\begin{array}{c}\text { VAB Agrop./ } \\
\text { VAB Total - } \\
\text { Dados do } \\
\text { Municipal } \\
(\%)(1) \\
\end{array}$ & $\begin{array}{c}\text { VAB } \\
\text { Ind.NAB } \\
\text { Total - } \\
\text { Dados do } \\
\text { Municipal } \\
\text { (\%)/(2) } \\
\end{array}$ & $\begin{array}{c}\text { VAB } \\
\text { Serv.NAB } \\
\text { Total - } \\
\text { Dados do } \\
\text { Municipal } \\
(\%)(3) \\
\end{array}$ & $\begin{array}{l}\text { PIB Per Capita } \\
(\mathrm{R} \$)(4)\end{array}$ & \begin{tabular}{|c|} 
Rendimento \\
Domiciliar Anual \\
per capita $(\mathrm{R} \$)^{(5)}$
\end{tabular} & $\begin{array}{l}\text { Rend.Domiciliar } \\
\text { Anual per capita / } \\
\text { PIB per Capita } \\
\text { (R\$) }\end{array}$ \\
\hline Chapecó & 183530 & 168113 & 15417 & 8,40 & 3,26 & 30,24 & 66,51 & 25087,44 & 4362,85 & 17,39 \\
\hline Concórdia & 68621 & 54865 & 13756 & 20,05 & 11,09 & 29,27 & 59,64 & 24336,01 & 4425,22 & 18,18 \\
\hline Maravilha & 22101 & 18087 & 4014 & 18,16 & 5,80 & 38,54 & 55,66 & 28401,57 & 4149,45 & 14,61 \\
\hline Pinhalzinho & 16332 & 13615 & 2717 & 16,64 & 6,02 & 44,52 & 49,47 & 33466,75 & 3852,10 & 11,51 \\
\hline $\begin{array}{r}\text { São Miguel do } \\
\text { Oeste }\end{array}$ & 36306 & 32065 & 4241 & 11,68 & 4,10 & 32,74 & 63,16 & 24736,05 & 4966,62 & 20,08 \\
\hline Xanxerêt & 44128 & 39143 & 4985 & 11,30 & 9,20 & 32,71 & 58,09 & 23601,59 & 3740,05 & 15,85 \\
\hline Reglão de & 371018 & 325888 & 45130 & 12,16 & 5,65 & 32,02 & 62,32 & 25303,62 & 4324,20 & 17,09 \\
\hline
\end{tabular}

Fonte: IBGE, Censo Demográfico 2010; Diretoria de Contas Nacionais.

Nota: VAB - Valor Adicionado Bruto; (1) Valor Adicionado Bruto da Agropecuária; (2) Valor Adicionado Bruto da Indústria; (3) Valor Adicionado Bruto de Serviços;

(4) Produto Interno Bruto; (5) Exclusive o rendimento das pessoas cuja condição no domicílio era: pensionista, empregado(a) doméstico(a) ou parente do

empregado(a) doméstico(a).

Nota: 1) Estrutura do Valor Adicionado Bruto; (1) Agropecuária; (2) Indústria; (3) Serviços.

Ao analisar a relação Rendimento Domiciliar (RD) Anual per capita/PIB per capita, depara-se com um percentual de apropriação da renda de 17,09\%, em 2010, e 11,29\%, em 2014, por parte dos indivíduos da região. Essa redução (de 17,09\% para 11,29\%) observada na região como um todo também se verifica na comparação individual de cada um dos municípios no mesmo período. Tal fenômeno pode ser considerado um indício de aumento na desigualdade social, embora, devido à carência de uma base de dados mais extensa, não seja possível identificar a causa do fenômeno, nem mesmo se este é uma tendência ou um evento isolado. Logo, para fins economicistas, esta questão exigiria uma nova pesquisa com vista à identificação da causalidade do fenômeno. 
Tabela 2 - Indicadores de população e Macrossetores produtivos da Região de pesquisa 2014 (tendo como referência 2010)

\begin{tabular}{|c|c|c|c|c|c|c|c|c|c|c|}
\hline Municípios & $\begin{array}{l}\text { População Total } \\
\text { (n' }{ }^{\circ} \text { habitantes) }\end{array}$ & $\begin{array}{l}\text { População } \\
\text { Urbana ( }{ }^{\circ} \\
\text { habitantes) }\end{array}$ & $\begin{array}{c}\text { População } \\
\text { Rural (nº } \\
\text { habitantes) }\end{array}$ & $\begin{array}{c}\text { Pop } \\
\text { rural/Pop } \\
\text { Total (\%) }\end{array}$ & $\begin{array}{l}\text { VAB Agrop./ } \\
\text { VAB Total - } \\
\text { Dados do } \\
\text { Municipal } \\
(\%)(1) \\
\end{array}$ & $\begin{array}{c}\text { VAB } \\
\text { Ind./VAB } \\
\text { Total - } \\
\text { Dados do } \\
\text { Municipal } \\
(\%)(2) \\
\end{array}$ & $\begin{array}{c}\text { VAB } \\
\text { Serv./VAB } \\
\text { Total - } \\
\text { Dados do } \\
\text { Municipal } \\
(\%)(3) \\
\end{array}$ & $\begin{array}{l}\text { PIB Per Capita } \\
\text { (R\$)(4) }\end{array}$ & $\begin{array}{c}\text { Rendimento } \\
\text { Domiciliar Anual } \\
\text { per capita }(R \$)^{(5)}\end{array}$ & $\begin{array}{l}\text { Rend.Domiciliar } \\
\text { Anual per capita / } \\
\text { PIB per Capita } \\
\text { (R\$) }\end{array}$ \\
\hline Chapecó & 209553 & 191950 & 17603 & 8,40 & 2,16 & 36,45 & 61,38 & 36809,81 & 3821,05 & 10,38 \\
\hline Concórdia & 73206 & 58531 & 14675 & 20,05 & 11,43 & 24,37 & 64,19 & 29543,62 & 4148,07 & 14,04 \\
\hline Maravilha & 24712 & 20224 & 4488 & 18,16 & 5,09 & 50,23 & 44,68 & 34868,32 & 3711,03 & 10,64 \\
\hline Pinhalzinho & 19105 & 15927 & 3178 & 16,64 & 6,98 & 47,73 & 45,29 & 44303,48 & 3292,98 & 7,43 \\
\hline $\begin{array}{r}\text { São Miguel do } \\
\text { Oeste }\end{array}$ & 39390 & 34789 & 4601 & 11,68 & 6,76 & 33,95 & 59,30 & 30883,52 & 4577,76 & 14,82 \\
\hline Xanxerê & 49057 & 43515 & 5542 & 11,30 & 7,77 & 31,52 & 60,72 & 28780,58 & 3364,27 & 11,69 \\
\hline $\begin{array}{r}\text { Região de } \\
\text { Pesquisa }\end{array}$ & 415023 & 364935 & 50088 & 12,07 & 4,96 & 35,49 & 59,55 & 34245,94 & 3865,70 & 11,29 \\
\hline
\end{tabular}

Fonte: IBGE, Censo Demográfico 2010; Diretoria de Contas Nacionais.

Nota: VAB - Valor Adicionado Bruto; (1) Valor Adicionado Bruto da Agropecuária; (2) Valor Adicionado Bruto da Indústria; (3) Valor Adicionado Bruto de Serviços;

(4) Produto Interno Bruto; (5) Exclusive o rendimento das pessoas cuja condição no domicílio era: pensionista, empregado(a) doméstico(a) ou parente do

empregado(a) doméstico(a).

Nota: 1) Estrutura do Valor Adicionado Bruto; (1) Agropecuária; (2) Indústria; (3) Serviços.

2) VAB (2014): série revisada tendo como referencia 2010.

Por fim, para que se tenham melhores pistas do potencial da região, faz-se necessário o uso da racionalidade do Quociente Locacional, a fim de mensurar o grau de especialização relativa da região. Para isto, adotou-se neste estudo duas situações em que a medida de especialização se aplica a uma região de referência.

Tabela 3 - Estrutura do VAB por macrossetor produtivo (x1000) R\$ -- 2014

\begin{tabular}{lrrrr}
\hline & VAB Agropecuária & VAB Indústria & VAB Serviços & VAB Total \\
\hline Chapecó & $131.639,00$ & $2.219 .874,00$ & $3.737 .917,00$ & $6.089 .430,00$ \\
Concórdia & $188.553,00$ & $401.901,00$ & $1.058 .573,00$ & $1.649 .027,00$ \\
Maravilha & $34.598,00$ & $341.573,00$ & $303.814,00$ & $679.985,00$ \\
São Miguel do oeste & $65.809,00$ & $330.494,00$ & $577.307,00$ & $973.610,00$ \\
Pinhalzinho & $47.764,00$ & $326.362,00$ & $309.711,00$ & $683.837,00$ \\
Xanxerê & $86.419,00$ & $350.744,00$ & $675.686,00$ & $1.112 .849,00$ \\
Região de pesquisa & $554.782,00$ & $3.970 .948,00$ & $6.663 .008,00$ & $11.188 .738,00$ \\
Estado de Santa Catarina & 12.677 .000 & 62.123 .000 & 130.034 .000 & 204.834 .000 \\
\hline
\end{tabular}

Fonte: IBGE Cidades (base 2014)

A Tabela 4 apresenta os QL's dos municípios tendo como referência a Microrregião de Chapecó. Por sua vez, a Tabela 5 apresenta os QL's dos municípios e da Microrregião de Chapecó, tendo como referência o estado de Santa Catarina. 
Tabela 4 - Medida de especialização (QL) por macrossetor produtivo da região de pesquisa e dos municípios em relação ao Estado de Santa Catarina

\begin{tabular}{lrrr}
\hline & Agropecuária & Indústria & Serviços \\
Chapecó & 0,3493 & 1,2020 & 0,9669 \\
Concórdia & 1,8475 & 0,8036 & 1,0112 \\
Maravilha & 0,8221 & 1,6563 & 0,7038 \\
São Miguel do Oeste & 1,0922 & 1,1193 & 0,9340 \\
Pinhalzinho & 1,1286 & 1,5736 & 0,7134 \\
Xanxerê & 1,2548 & 1,0392 & 0,9564 \\
Região de pesquisa & 0,8012 & 1,1702 & 0,9381 \\
\hline
\end{tabular}

Fonte: IBGE Cidades (base 2014).

Os QL's foram calculados a partir de dados da Tabela 3, tendo 2014 como ano de referência. Para fins práticos adota-se: para $Q L^{\prime}$ 's $\leq 1$, como sinônimo de não especialização relativa e $Q L^{\prime}$ ' $>1$ como sinônimo de especialização relativa, sendo que quanto maior o QL, maior será a especialização relativa de um setor em detrimento da região de referência

Tabela 5 - Medida de especialização (QL) por macrossetor produtivo dos municípios em relação à região de pesquisa

\begin{tabular}{lrrr}
\hline & Agropecuária & Indústria & Serviços \\
\hline Chapecó & 0,4360 & 1,0272 & 1,0308 \\
Concórdia & 2,3060 & 0,6867 & 1,0780 \\
Maravilha & 1,0261 & 1,4154 & 0,7503 \\
São Miguel do Oeste & 1,3632 & 0,9565 & 0,9957 \\
Pinhalzinho & 1,4087 & 1,3447 & 0,7605 \\
Xanxerê & 1,5661 & 0,8881 & 1,0196 \\
\hline
\end{tabular}

Fonte: IBGE Cidades (base 2014) em dados de 2014.

De acordo com a Tabela 4, que apresenta a medida de especialização relativa dos municípios tendo como referência a Microrregião de Chapecó, observa-se que o setor agropecuário é o que apresenta maior especialização relativa por número de municípios, apresentando QL > 1 em cinco dos seis municípios, cuja única exceção foi Chapecó que apresentou um QL agropecuário de 0,4360. Entre os demais, Concórdia é o município que apresenta o QL agropecuário mais expressivo (2,3060). A indústria apresentou QL's > 1 em três municípios (Chapecó Maravilha e Pinhalzinho), com destaque para Maravilha, que 
apresentou o maior QL no setor (1,4154); já o setor serviços apresentou QL's > 1 em três municípios (Chapecó, Concórdia e Xanxerê).

De acordo com a Tabela 5, que apresenta a medida de especialização relativa dos municípios e da Microrregião de Chapecó tendo como referência o estado de Santa Catarina, observa-se que o setor da indústria é o que apresenta maior especialização relativa por número de municípios, apresentando $Q L>1$ em cinco dos seis municípios, sendo que a única exceção foi Concórdia, que apresentou um QL de 0,8036 no setor. Entre os demais, Maravilha novamente é o município que apresentou o maior QL da indústria $(1,6563)$. setor agropecuário apresentou QL's > 1 em quatro municípios (Concórdia, Pinhalzinho, São Miguel do Oeste e Xanxerê), sendo novamente Concórdia o município com maior QL agropecuário (1,8475). O setor serviços apresentou QL's > 1 apenas no município de Concórdia, apresentando um QL de 1,0112 no setor. A região de pesquisa apresentou QL > 1 apenas no macrossetor indústria $(1,1702)$.

\subsection{Apresentação e discussão dos dados}

Identificar o potencial de uma região, com vista ao planejamento para o desenvolvimento endógeno, tem como ponto de partida a identificação dos fatores produtivos que a região possui e que se encontram subutilizados ou utilizados de forma subótima. Uma vez identificados, faz-se necessária a mensuração do capital social, humano e institucional, com vista à mobilização político-econômica local, na qual se torna possível o processo de endogenização da geração e distribuição da riqueza por parte dos agentes locais. Assim, pressupõe-se que os agentes locais, ao interagirem em laços de cooperação local/regional, possam tornar-se protagonistas do desenvolvimento econômico-social da região.

Uma análise dos dados apresentados no item 4.1 exige, primeiramente, a categorização da região e seus municípios quanto a sua tipicidade dada sua estrutura produtiva com base no peso relativo de cada macrossetor. Isto tem como objetivo verificar em quais setores residem as principais suspeitas de potencial.

Primeiramente, descarta-se a possibilidade da região e seus municípios serem tipicamente rurais, uma vez que, segundo Paiva (2004), as regiões tipicamente rurais 
apresentam participação do VAB agropecuária/VAB total superior a 30\%. A próxima suspeita de potencial reside no setor industrial, a partir do qual, segundo Paiva (2004), pode-se passar a suspeitar da existência de potencialidades imediatas na indústria regional quando a relação VAB industrial/VAB total é superior a $25 \%$, o que, de acordo com os Gráficos 3, 6 e 7, verificase na região e em todos os seus municípios, com exceção de Concórdia (2014).

Ainda de acordo com os Gráficos 3, 6 e 7, é possível verificar a expressiva relação $V A B$ serviços/VAB total na região e nos municípios. Esta relação é, na região (e quase sempre nos municípios), superior a 50\%, o que, segundo Paiva (2004), pode representar a estruturalidade da crise produtiva da economia regional. Num primeiro momento, a questão não pode ser encarada como sentença final da análise de desenvolvimento regional, uma vez que a expressiva participação do setor serviços no VAB total, no que diz respeito à produtividade no setor, pode se caracterizar em dois sentidos:

[...] de um lado, uma elevada produtividade em serviços - particularmente quando a medida é captada para municípios que já são (ou estão se constituindo como) pólos regionais - é um indicador de possibilidade de expansão da rede de serviços interna com vistas a atender a demandas da periferia regional; de outro lado, uma produtividade particularmente baixa no setor serviços pode ser a expressão de um gargalo limitador da dinâmica regional. Particularmente, os municípios e as microrregiões que se encontram relativamente afastados dos pólos consumidores responsáveis pela absorção de sua produção mercantil de exportação precisam contar com serviços de comercialização e transporte suficientemente produtivos e econômicos para contrabalançar as desvantagens nos custos de transporte (PAIVA, 2004, p. 31).

Pesquisas anteriores (MAIA; SANTIN; ALBA; VILLELA, 2014; MAIA; LUDWIG, 2013) mostram a importância da agroindústria na região, a qual é capaz de promover a integração entre os setores agropecuário, industrial e de serviços. Este processo de integração tem trabalhado na formação e consolidação de clusters regionais.

A integração entre os setores agropecuário, da indústria e de serviços, bem como a característica de micropólos regionais, que os municípios assumem no oeste catarinense, pode ser um indício da capacidade de expansão do setor serviços na região. Neste caso, a elevada participação na relação VAB serviços/VAB total perde sua característica de gargalo e passa a ser considerada como agente potencializador do desenvolvimento regional. Como prova disso, a Tabela 5 mostra que, apesar da elevada relação VAB serviços/VAB total, o setor que apresenta o maior número de $Q L^{\prime} s$ > 1 é a indústria, seguida pelo setor 
agropecuário. Enquanto o setor serviços apresentou QL > 1 em apenas um município (Concórdia), com QL = 1,0112, a região de pesquisa, por si só, apresentou QL > 1 apenas na indústria $(1,1702)$.

Quanto à categorização da região, pode-se lançar luz sobre o fato dessa ser uma região que vem se consolidando como industrial, primeiramente por ser responsável por 6,39\% do VAB da indústria no estado de Santa Catarina (Gráfico 1), mesmo sendo composta por apenas seis municípios dentre os 295 do total estadual. Em seguida, observa-se que a indústria corresponde a mais de $25 \%$ do VAB total da região. Por fim, a indústria foi o único setor produtivo que apresentou $Q \mathrm{~L}>1$ para a região de pesquisa na análise Microrregião de Chapecó tendo como referência Santa Catarina (Tabela 5).

A caracterização da região como industrial não menospreza a agropecuária ou o rural, uma vez que ambos estão interligados, e o sucesso da indústria na região está intimamente ligado à formação dos clusters agroindustriais.

\section{Considerações finais}

Neste estudo, identificou-se potencialidades no setor industrial da região, setor que vem ganhando espaço na economia regional nas últimas décadas. Parte do desenvolvimento do setor provém da integração entre agropecuária, indústria e serviços, que, juntos, formam uma cadeia produtiva (principalmente quanto à atividade agroindustrial) e agem para a formação de clusters regionais. A atividade industrial vem ganhando destaque, em especial nos municípios Maravilha e Pinhalzinho, deixando a desejar apenas no município de Concórdia, dada a sua baixa relação VAB indústria/VAB total e ao seu $Q L$ industrial $<1$, o que indica não especialização relativa no setor.

Maravilha, por apresentar o maior QL industrial, a maior relação VAB industrial/VAB total $(50,23 \%$ em 2014$)$ e o maior crescimento da participação do setor no VAB total de 2010 a 2014, apresentando um crescimento de 30,47\%, pode ser considerado como micropólo tipicamente industrial, uma vez que essa atividade é a força motriz de sua economia. Situação semelhante encontra-se em Pinhalzinho, cuja relação VAB industrial/VAB total foi 
de 47,63\%, em 2014, apresentando o segundo maior QL industrial dentre os municípios e tendo um crescimento de 7,03\% no setor de 2010 a 2014.

Em relação ao setor industrial, conforme este estudo, pode-se considerar que não é necessariamente a centralidade da indústria a responsável pelo processo de desenvolvimento regional, mas é o crescimento dos serviços auxiliares e das indústrias subsidiárias, que são a base da produção e comercialização eficiente do produto de exportação da região. Ou seja, é a partir do desenvolvimento de indústrias locais, para servirem ao consumo local, que se verifica o crescimento das áreas e serviços urbanos, o que também incorre num certo investimento crescente na educação e na pesquisa, ampliando o potencial da região ${ }^{4}$, dada à ampliação por parte dessas indústrias da base de exportação, em consequência da expansão dos mercados e do desenvolvimento de economias externas, associadas com a indústria de exportação.

A relação Rendimento Domiciliar (RD) Anual per capita/PIB per capita mostra que existe pouca disparidade interna entre os municípios, uma vez que, em 2014, o município que possui o menor percentual de apropriação da renda por parte dos indivíduos foi Pinhalzinho $(7,43 \%)$, e o município que apresentou o maior percentual foi São Miguel do Oeste (14,82\%). Neste estudo, a relação Rendimento Domiciliar (RD) Anual per capita/PIB per capita é complementar, uma vez que num primeiro momento o que interessa é identificar os setores que apresentam maior potencial, a partir do estudo dos QL's e do VAB.

Uma vez identificados quais os setores que possuem o maior potencial em uma região, pode-se partir para uma análise específica destes setores com base em novas pesquisas, com vista à identificação de novas potencialidades e gargalos ao desenvolvimento regional endógeno.

\section{Referências}

BECKER, Dizimar Fermiano. A economia política do (des)envolvimento regional. Redes, v. 7, n. 3. p. 35-59, set./dez. 2002.

\footnotetext{
${ }^{4}$ North (1959, p. 341) descreve uma série de condições necessárias para que uma atividade agrícola seja bemsucedida, de modo a constituir a base de exportação e proporcionar um aumento de renda regional.
} 
BENKO, Georges. 1999. Economia, espaço e globalização na aurora do século XXI. São Paulo, Hucitec, 2999. 226 p.

BREITBACH, Áurea. Estudo sobre o conceito de região. Porto Alegre: FEE, 1988.

COSTA, José Silva; PETER, Nijkamp. Compêndio de economia regional. Volume II, Métodos e técnicas de análise regional. Parede-Portugal: Princípia, 2011.

COSTA, José Silva; NIJKAMP, Peter. Compêndio de economia regional. Volume I, Teoria, temáticas e políticas. Cascais: Princípia, 2009.

DINIZ, Clélio Campolina; CROCCO, Marco. Economia Regional e Urbana: contribuições teóricas recentes. Minas Gerais: UFMG, 2006.

Global-Local: interdependências e desigualdades ou notas para uma política tecnológica e industrial regionalizada no Brasil. Rio de Janeiro: CEDEPLAR/IE/UFRJ, 2000.

FUJITA, Camila; MATIELLO, Alexandre; ALBA, Rosa Salete. Rede de polo e micropolos regionais no oeste catarinense. Redes. v. 14, n. 2, maio/ago., 2009.

HADDAD, Paulo R. (org.) Economia Regional: teorias e métodos de análise. Fortaleza: BNB, 1989.

MACEDO, Guilherme; MONASTERIO, Leonardo. Local Multiplier of Industrial Employment: Brazilian Mesoregions (2000-2010). Revista de Economia Política (Impresso), v. 36, p. 827-839, 2016.

MAIA, Claudio Machado; RIEDL, Mario; SCHUSTER, Celso. Análise regional do COREDE Nordeste. Perspectiva Econômica (online), v. 4, p . 65 - 85, 2008. Disponível em http://www.perspectivaeconomica.unisinos.br/pdfs/83.pdf. Acesso em: 1 ago. 2017.

MAIA, Claudio Machado; SANTIN, Myriam Aldana Vargas; ALBA, Rosa Salete; VILLELA, Ana Laura Vianna. Metropolização e Condições de Urbanização: Novas Territorialidades e Novas Dinâmicas Espaciais em Cidades de Maior Influência no Oeste Catarinense. In: $2^{\circ}$ Seminário de Desenvolvimento Regional, Estado e Sociedade (SEDRES). A Diversidade Regional Brasileira em Perspectiva, Anais GT6. Campina Grande/PB: EDUEPB/UEPB, 2014.

MAIA, Claudio Machado; LUDWIG, Dione Paula. Novas territorialidades regionais no oeste catarinense: reestruturação produtiva e urbana das cidades de maior influência da região. In: 1ํo Seminário Nacional de Planejamento e Desenvolvimento. Curitiba/PR, 2013.

MAIA, Claudio Machado; ROLIM, Aparício. O processo de metropolização e condições de urbanização: novas territorialidades e novas dinâmicas espaciais em cidades de maior influência no oeste catarinense. In: Seminário Internacional Culturas e Desenvolvimento (SICDES), II Congresso Sul-Brasileiro de Promoção dos Direitos Indígenas (CONSUDI) e $\checkmark$ Colóquio Catarinense de Ensino Religioso, 2015, Chapecó/SC. 
MAIA, Claudio Machado; FUJITA, Camila; ALBA, Rosa Salete. Reestruturação produtiva e dinâmica urbana e regional no oeste catarinense: uma análise do papel de Chapecó e outras cinco cidades influentes. In: XV Encontro da Associação Nacional Planejamento Urbano e Regional. Recife/PR: XV ENANPUR, 2013.

NORTH, Douglas. Agriculture in regional economic growth. Journal of Farm Economics, Lancaster, Pa., US: American Farm Economic Associoation, v. 4, n. 5, p. 333, dec. 1959.

Location theory and regional economic growth. Journal of Political Economy, Chicago, III., US: University of Chicago Press, n. 43, p. 291, jun. 1955.

PAIVA, Carlos Águedo Nagel. Como identificar e mobilizar o potencial de desenvolvimento endógeno de uma região? In: Documentos FEE, n. 59. Porto Alegre: FEE, 2004.

. Desenvolvimento Endógeno e Potencialidades Regionais. Porto Alegre: FEE, 2006a. 21 p. [mimeo].

Desenvolvimento Regional, Especialização e suas Medidas. In: Indicadores Econômicos. v. 16. n. 2. Porto Alegre: FEE, 2006b.

. Fundamentos da análise do planejamento de economias regionais. Foz do Iguaçu: Parque Itaipu, 2013.

Regionalização com vistas ao planejamento do desenvolvimento endógeno sustentável. In: Primeiras Jornadas de Economia Comparada, 1, Porto Alegre 2005. Anais... Porto Alegre, FEE/PUCRS, 2005.

. Re-regionalizar o RS para planejar o desenvolvimento endógeno dos territórios retardatários: um programa de pesquisa em curso. Porto Alegre: FEE, 2006c. 13 p. [mimeo].

VILLELA, Ana Laura Vianna; ALBA, Rosa Salete; MAIA, Claudio Machado; ARRUDA, Laiz. Região Metropolitana de Chapecó: dinâmicas regionais e suas territorialidades. In: II Encontro Nacional de tecnologia Urbana (ENURB). Anais II Encontro Nacional de tecnologia Urbana. Passo Fundo/RS: UPF, 2015. 